\title{
Management outcome of blunt renal trauma in a tertiary level hospital of Bangladesh
}

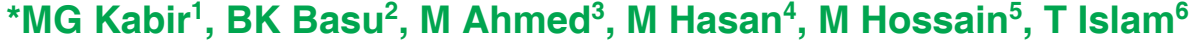

\begin{abstract}
Background: The kidney is the commonly injured genitourinary and abdominal organ. Renal injuries are classified by their mechanism: blunt or penetrating. Failure to perform appropriate evaluation and treatment of these injuries may result in significant long term patient morbidity. Objective: To evaluate blunt renal trauma cases at a tertiary level hospital to find out management practices along with patient outcomes. Methods: This prospective observational study was conducted in the Department of Urology of Dhaka Medical College Hospital during the period of January 2011 to December 2012 to observe the management outcome of blunt kidney injuries. Sampling technique was purposive and sample size was 110. After management of blunt kidney injury by either conservatively or by surgical means, some patients were followed up for 2 years and others for less than 2 years. Results: In this study, 90.1\% patients were diagnosed and staged by contrast enhanced CT scan. Most of the early grade injuries (grade I-III) were treated conservatively and outcome in terms of surgical conversion and short term complications were favourable. Few bluntly injured grade IV and $\mathrm{V}$ required operative interventions. Overall nephrectomy rate was only $3.6 \%$. Haemodynamic instability, associated organ injury, higher grade injury - all were predictive indicators of operative interventions. The study showed that rates of complications were more in higher grade injury, with concomitant other organ injuries and in patients who required blood transfusion (indicator of hemodynamic instability). Conclusion: Most of the blunt kidney injuries can be managed in conservative way with favourable outcome.
\end{abstract}

Keywords: Renal trauma, Blunt injury, Conservative management, Favourable outcome.

\section{Introduction}

About $10 \%$ of all injuries seen in the emergency room involve the genitourinary system. Renal injury is reported in $3 \%$ of trauma patients. Renal injuries are classified by their mechanism: blunt or penetrating. The majority $(>90 \%)$ are due to blunt mechanisms of injury. Blunt trauma is usually caused by motor vehicle accidents, falls, vehicle-associated pedestrian accidents, contact sports and assault. $^{1}$

\footnotetext{
1. Dr. MD Golam Kabir, Assistant Professor, Department of Urology, Khulna Medical College Hospital, Khulna. Email: gkgsdmc@yahoo.com.

2. Professor Dr. Banga Kamal Basu, Head of the Department of Surgery and Principal, Gazi Medical College, Khulna.

3. Dr. Masud Ahmed, Assistant professor, Department of Urology, Khulna Medical College Hospital, Khulna.

4. Dr. Mahmud Hasan, Assistant Professor, Department of Urology, Mugda Medical College, Dhaka.

5. Dr. Moajjam Hossain, Assistant Professor, Department of Urology, Shaheed Sheikh Abu Naser Specialized Hospital, Khulna.

6. Dr. Tarikul Islam, Assistant professor, Department of Burn and plastic surgery, Khulna Medical College Hospital, Khulna.
} 
Minor renal injuries pose few management difficulties and the majority can be managed by conservative way. But renal parenchymal lacerations and vascular injuries can be life-threatening and have been managed by operative intervention with repair of the injured kidney when possible. In recent days there has been a trend towards non-operative management of all solid intra-abdominal organ injury including renal trauma. But many of them are subtle and difficult to define and require great diagnostic expertise. Early diagnosis is essential to prevent serious complications. Failure to appropriately evaluate and treat these injuries may result in significant long term patient morbidity. Advances in imaging and treatment strategies during the past 20 years have decreased the need for surgical intervention and increased renal preservation.

The incidence, severity and optimal treatment of renal injuries have not been established in population-based cross-sectional studies or prospective trials previously in Bangladesh. Hundreds of published reports have discussed the treatment of renal trauma, but regional differences in injury mechanisms and treatment preferences and available facilities (such as physical assault is one of the frequent mechanisms of blunt renal trauma in our country; similarly embolization for controlling bleeding vessels is not widespread in our country) may make it inappropriate to generalize the findings of specialized centers to practitioners worldwide.

The aim of this study is the evaluation of management outcome of various types of blunt renal injuries in our perspective. This study will give some insight for appropriate evaluation and management outcome of various types of blunt renal injuries and may help the physicians to formulate a guideline for the management of renal trauma.

\section{Methodology}

This prospective observational study was done in urology and casualty departments of
Dhaka Medical College Hospital, Dhaka for a period of 2 years extending from January 2011 to December 2012 to observe the outcome of various types of blunt kidney injuries. A total of 110 patients admitted with blunt renal injury at $\mathrm{DMCH}$ and among them, who gave consent to participate were consecutively included in the study.

Findings on physical examination such as haematuria, flank pain, flank abrasions and ecchymoses, fractured ribs, abdominal tenderness, distension or mass could indicate possible renal involvement. ${ }^{2}$

All patients presenting with kidney injury were initially assessed and resuscitated according to Advanced Trauma Life Support guidelines. ${ }^{2}$

After admission, patients were selected for this study according to selection criteria. All the patients, whose renal injury was not proved definitely, penetrating mechanism of injury, patients who refused to give informed consent, associated urethral injury or pelvic fracture and associated head and spinal cord injuries were excluded from the study.

Those who could be stabilized underwent staging CT and were treated by conservative way. The treatment consisted of bed rest until gross haematuria resolved, prophylactic antibiotics, serial haematocrit measurements and close clinical observation with advice of avoidance of strenuous physical exertion for 6 weeks. Few patients required delayed surgery or minimal invasive procedure for development of complications. Patients who could not be stabilized or who required multiple blood transfusions underwent surgical exploration immediately. The methods of renal repair were all within accepted standard clinical practices of nephrectomy, partial nephrectomy and renorraphy. Some needed immediate surgery whereas few needed delayed surgery due to development of complications.

All the patients included in this study were informed about the nature, risk and benefit about study and written informed consent was taken. Patients were evaluated by clinical 
history, physical examinations and necessary investigations. Before proceeding to operative procedure, proper and detailed counseling was done with the patients regarding the operative procedure, anesthesia, possible complications and management, postoperative follow up and investigations and regarding study inclusion.

The patients consumed normal diet after appearance of bowel sound. The patients were ambulated on the first postoperative day. Drain tube was removed after 24 hours if no collection was seen and patients were usually discharged with advice after 7 days if no complications developed. All the patients were counseled and requested to attend for follow up at mentioned date and place with reports of investigations. Some patients were followed up 2 years and others were less than 2 years due to duration of study by history regarding blood pressure, fever, hematuria, other urinary symptoms, examination of external genitalia, both loin, and systemic examination when necessary. Among the investigations, urine for routine and microscopic examination for pus cells, RBC and culture to exclude infection, ultrasonogram of kidney, ureter and bladder region and occasionally CT scan was done.

Injuries were classified according to the renal injury scale defined by the American Association for the Surgery of Trauma, i.e. grade I to grade $\mathrm{V}$.

Data collection was carried out according to a pre-designed questionnaire form and by trained physicians who filled in the forms of whole referred traumatic patients to the above mentioned department 24 hours a day. Direct observation and interview were the method of data collection. The collected data included demographic characteristics, trauma mechanism, severity of injury, associated injuries, investigations findings, details about treatment including both conservative and operative findings and follow up with complications details were assessed by both manual and computer based statistical analysis to determine the relationship with various blunt renal injury outcomes including the requirement and type of surgical intervention and the need for nephrectomy. The outcomes evaluated were requirement of surgical intervention, type of surgical intervention, need for nephrectomy and various short term complications.

\section{Results}

Of the 110 patients, 100 were diagnosed by contrast enhanced CT scan of abdomen and pelvis, USG of KUB (81.8\%) and Urinalysis (78.2\%) was used mainly either for preliminary or adjunct to diagnosis.

Table 01: Investigations done for diagno$\operatorname{sis}(n=110)$

\begin{tabular}{lll}
\hline Name of Investigation & Frequency & Percentage \\
\hline Urinalysis & 86 & 78.2 \\
USG of KUB & 90 & 81.8 \\
Contrast enhanced & 100 & 90.9 \\
CT scan of & & \\
Abdomen and Pelvis & & \\
\hline
\end{tabular}

Table 02 shows $41.8 \%$ were grade I, 20\% were grade II, both grade III and IV were $17.3 \%$ and grade $V$ were $3.6 \%$

Table 02: Distribution of patients by grade of injury $(n=110)$

\begin{tabular}{lll}
\hline Type of Injury & Frequency & Percentage \\
\hline Grade I & 46 & 41.8 \\
Grade II & 22 & 20.0 \\
Grade III & 19 & 17.3 \\
Grade IV & 19 & 17.3 \\
Grade V & 4 & 2.6 \\
\hline
\end{tabular}


Table 03 shows different organ injuries were found in blunt or indirect violence. Liver was the most injured organ $(8.2 \%)$ followed by small intestine $(4.5 \%)$

Table 03: Distribution of patients by organ injury in blunt renal trauma $(n=110)$

\begin{tabular}{ccc}
\hline $\begin{array}{c}\text { Organ } \\
\text { injury }\end{array}$ & Frequency & Percentage \\
\hline Liver & 9 & 8.2 \\
Spleen & 2 & 1.8 \\
Colon & 2 & 1.8 \\
Small & 5 & 4.5 \\
intestine & & \\
Pancreas & 2 & 1.8 \\
\hline
\end{tabular}

Table 04 shows that most of the patients $(71.8 \%)$ were treated conservatively.

Table 04: Distribution of patients by type of treatment $(n=110)$

\begin{tabular}{ccc}
$\begin{array}{c}\text { Total no of } \\
\text { patients }\end{array}$ & $\begin{array}{c}\text { Conservative } \\
\text { treatment }\end{array}$ & $\begin{array}{c}\text { Surgical } \\
\text { treatment }\end{array}$ \\
\hline 110 & $79(71.8 \%)$ & $31(28.2 \%)$
\end{tabular}

Table 05 shows various types of immediate surgery in bluntly injured renal trauma patients. Of 110 patients, 15 (13.6\%) required exploratory laparotomy due to associated organ injury, 11 (10\%) patients underwent renal exploration only. Renorraphy, partial nephrectomy and total nepherectomy required in $5(4.5 \%), 2(1.8 \%)$ and $2(1.8 \%)$ patients respectively.

Table 05: Distribution of patients by various types of immediate surgery done with blunt renal trauma

\begin{tabular}{llllllll}
\hline \multicolumn{1}{c}{ Type of treatment } & \multicolumn{6}{c}{ Grade of injury $(\mathrm{n}=110)$} & \multirow{2}{*}{ Total } \\
& I & II & III & IV & V & \\
\hline $\begin{array}{l}\text { Exploration with associated } \\
\text { organ injury with or without renal } \\
\text { exploration }\end{array}$ & 1 & 2 & 5 & 5 & 2 & $15(13.6 \%)$ \\
\hline $\begin{array}{l}\text { Renal exploration only (opening } \\
\text { of Gerotas fascia) }\end{array}$ & - & 2 & 5 & 4 & - & $11(10 \%)$ \\
\hline Renorraphy & - & 1 & 3 & 1 & - & $5(4.5 \%)$ \\
\hline Partial Nephrectomy & - & - & 2 & - & - & $2(1.8 \%)$ \\
\hline Total Nephrectomy & - & - & - & - & 2 & $2(1.8 \%)$ \\
\hline
\end{tabular}

Table 06 shows various types of delayed surgery in bluntly injury patients who initially underwent conservative treatment. Out of 110 patients embolization for bleeding for delayed hematuria, DJ stenting for urinoma, percutaneous drainage for perinephric abscess, delayed partial nephrectomy and delayed total nephrectomy for severe bleeding were done in $2(1.8 \%)$ patients in each. Total $10(9.2 \%)$ patients required delayed surgery who were initially under conservative treatment but later required surgery due to various complications.

Table 06: Distribution of patients by various types of delayed surgery with blunt renal trauma $(n=110)$

\begin{tabular}{llllll}
\hline \multirow{2}{*}{ Grade of injury } & \multirow{2}{*}{ Embolization } & \multirow{2}{*}{ DJ stenting } & $\begin{array}{l}\text { Percutaneous } \\
\text { drainage }\end{array}$ & $\begin{array}{l}\text { Delayed partial } \\
\text { Nephrectomy }\end{array}$ & $\begin{array}{l}\text { Delayed total } \\
\text { Nephrectomy }\end{array}$ \\
\hline I & - & - & - & - & - \\
II & - & - & - & - & - \\
III & - & - & 2 & 2 & - \\
IV & 2 & 2 & - & - & - \\
V & $2(1.8 \%)$ & $2(1.8 \%)$ & $2(1.8 \%)$ & $2(1.8 \%)$ & $2(1.8 \%)$ \\
\hline
\end{tabular}


Table 07 shows that, of the 79 patients treated conservatively $10.1 \%$ patients developed urinoma. The figure was $3.2 \%$ in patients who were treated surgically. Urinary extravasations or urinoma formation was more in conservatively treated patients. Overall $8.2 \%$ patients developed this complication.

Table 07: Distribution of patients by outcome of treatment in relation to extravasations /urinoma formation

\begin{tabular}{lllll}
\hline $\begin{array}{c}\text { Type of } \\
\text { treatment }\end{array}$ & Grade of injury & $\begin{array}{l}\text { Extravasations/ } \\
\text { urinoma formation }\end{array}$ & Grand Total & P Value \\
\hline & I & - & \\
Conservative & II & 2 & \\
$(=79)$ & III & 2 & \\
& IV & 4 & \\
Total & V & - & \\
& - & $8(10.1 \%)$ & \\
& I & - & \\
Surgery $(=31)$ & III & - & \\
& IV & - & \\
Total & V & 1 & \\
\hline
\end{tabular}

Table 08 shows that, of the 79 patients treated conservatively only $5.1 \%$ patients developed UTI. Hydronephrosis developed in $2.5 \%$ cases. Among surgically treated patients $6.4 \%$ developed perinephric abscess, 9.7\% developed UTI, 19.3\% developed wound infections and 6.4\% patients developed Reno-cutaneous fistula. UTI/pyelonephritis and Hydronephrosis were more in surgically treated patients.

Table 08: Distribution of patients by various complications after conservative and surgical treatment

\begin{tabular}{llll}
\hline Complications & \multicolumn{1}{l}{ Conservative treatment (=79) } & Surgical treatment (=31) & Grand total \\
\hline Perinephric abscess & - & $2(6.4 \%)$ & $2(1.8 \%)$ \\
\hline UTI/ Pyelonephritis & $4(5.1 \%)$ & $3(9.7 \%)$ & $7(6.4 \%)$ \\
\hline Wound infection & - & $6(19.3 \%)$ & $6(5.45 \%)$ \\
\hline $\begin{array}{l}\text { Renocutaneous } \\
\text { urinary fistula }\end{array}$ & - & $2(6.4 \%)$ & $2(1.8 \%)$ \\
\hline Hydronephrosis & $2(2.5 \%)$ & - & $2(1.8 \%)$ \\
\hline
\end{tabular}


Table 09 shows relation of renal injury complication in relation with associated organ injury. Out of 9 liver injuries, $4(44.4 \%)$ patients presented with hemodynamic instability. The rate was $100 \%$ in both spleen and pancreas injury. Moreover all the splenic injury cases later developed Reno-cutaneous-urinary fistula and the pancreatic cases developed perinephric abscess.

Table 09: Distribution of patients by relation of renal injury complications with associated organ injury

\begin{tabular}{llll}
\hline Associated organ injury & $\begin{array}{l}\text { Haemodynamic } \\
\text { instability }\end{array}$ & $\begin{array}{l}\text { Perinephric } \\
\text { abscess }\end{array}$ & Reno-cutaneous-urinary fistula \\
\hline Liver $(=9)$ & $4(44.4 \%)$ & - & - \\
Spleen $(=2)$ & $2(100 \%)$ & - & $2(100 \%)$ \\
Pancreas $(=2)$ & $2(100 \%)$ & $2(100 \%)$ & - \\
\hline
\end{tabular}

\section{Discussion}

In the last few decades the management of traumatic renal injuries has undergone a revolution from mandatory surgical exploration to non-operative care. More than $50 \%$ of all genitourinary trauma cases involve injury to the kidney. Renal injuries are theoretically more amenable to non-operative management than other intra $\neg$ abdominal solid organ injuries. The retroperitoneal position of the kidneys may contain hemorrhage and the rich blood supply may promote healing even after severe parenchymal injuries. Broghammer et al revealed non-operative or expectant care of renal injuries was first suggested in an article published more than 50 years ago (as cited in Moolman et al).3,4

Proponents of surgical treatment believe that the debridement of devascularized segments and closure of the collecting system maximize renal function and decrease complications such as persistent extravasations and delayed haemorrhage. ${ }^{5}$ With improvements in radiological imaging and the ready availability of CT, most patients with major renal trauma can also be followed expectantly, with delayed intervention only as needed. However, McAninch believed extensive extravasations, devitalized segments and coexisting bowel or pancreatic injuries are still considered relative indications for renal exploration (as cited in Moudouniet al). ${ }^{5}$ As few contemporary series addressed these injuries, we reviewed our experience by observing the various outcomes of the management of blunt renal injury.

In kidney trauma patients the haemodynamic situation is the benchmark for the diagnostic and therapeutic algorithm. Haemodynamically unstable patients require immediate laparotomy. Whenever the patient is stable enough to undergo imaging, a contrast enhanced CT scan is the best option to stage the trauma. The main goal of imaging is to differentiate injuries requiring early operative management from those amenable to deferred surgical treatment or non-operative management. ${ }^{6}$

Among the injuries $61.8 \%$ were grade I and II. Hammer and Santucci found similar result. ${ }^{7}$ Santucci et al found that most renal injuries were minor. ${ }^{6}$ Wessells and Mcaninch found that most renal injuries were grade I injuries. $^{8}$ In this study most of the $(71.8 \%)$ injuries were treated conservatively. Of 110 patients of bluntly injured renal trauma patients, 15 (13.6\%) required exploratory laparotomy due to associated organ injury with (8) or without (7) renal exploration, 11 (10\%) patients underwent renal exploration (opening of Gerotas fascia, no renal manipulation) only. Exploration for sole renal cause was 17. Renorraphy, partial nephrec 
tomy and total nephrectomy required in $5(4.5 \%), 2(1.8 \%)$ and $2(1.8 \%)$ patients respectively.

Three grade III blunt injuries required renorraphy; 2 of which due to undue explorations and 2 required partial nephrectomy, one of which was unnecessary due to loss of tamponade effect. One grade IV blunt trauma required renorraphy. Two (2) grade $\mathrm{V}$ blunt trauma required total nephrectomy due to shattered kidney. The study results are similar with the study of Aragona et al. ${ }^{9}$

There is the concern that routine renal exploration of all injured kidneys will result in an increased rate of nephrectomy (Velmahos et al cited in Moolman et al). ${ }^{4}$ The loss of a kidney, especially in the presence of other major associated injuries or septic complications, may also increase overall morbidity. Out of 110 patients of blunt injury embolization for bleeding (the facility was available in only few centers hence patient had to be referred to that centre), DJ stenting for urinoma, percutaneous drainage for perinephric abscess, delayed partial nephrectomy and delayed total nephrectomy for uncontrollable haemorrhage was done in $2(1.8 \%)$ patients in each. Total $10(9.2 \%)$ patients required delayed surgery who were initially under conservative treatment for various complications.

Eight (8) patients required immediate operation due to hemodynamic instability. Among them liver injury were in 4 cases, spleen injury in 2 cases and pancreatic injury were in 2 cases. Overall, nephrectomy was done in 4 (3.6\%) patients. Among them immediately was done in 2 patients; 2 in delayed cases due to continued bleeding. Among blunt grade $\mathrm{V}$ injury who underwent operation $50 \%$ required nephrectomy (2 patients).

A recent review of 8,465 patients with blunt and penetrating renal trauma showed an overall nephrectomy rate of $7.3 \%{ }^{4}$ Total partial nephrectomy cases were 4; out of which 2 cases were delayed partial nephrectomy. Immediate operation due to associated organ injury was in 15 patients.
Of the 79 patients treated conservatively $10.1 \%$ patients developed urinoma. The figure was $3.2 \%$ in patients who were treated surgically. Urinary extravasations or urinoma formation was more in conservatively treated patients, though a direct comparison could not be made here. Overall $8.2 \%$ patients developed this complication. Alsikafi et al found it in $3 \%$ patients in their cohort.10 Moudouni et concluded that extravasations associated with small renal lacerations would resolve spontaneously, while those associated with major lacerations would not and required exploration.5 Matthews et al reported $13 \%$ patients with major blunt renal lacerations and extravasation required ureteric stenting for persistent extravasation, while $27(87 \%)$ had spontaneous resolution of the extravasation. ${ }^{11}$ Complications requiring delayed intervention can be expected to occur with a conservative approach; persistent extravasation or urinoma was the 2nd most frequently reported complication $(10.1 \%)$ in the present series after hematuria. However, in contrast to other series, these complications were treated successfully with endo-urological methods and renal exploration was not required. Thus, although delayed intervention may require in some patients treated conservatively, complications are usually of low morbidity and can be managed successfully without renal exploration.

Of 79 patients treated conservatively, only $5.1 \%$ patients developed UTI. Hydronephrosis developed in $2.5 \%$ cases. Among surgically treated patients $6.4 \%$ patients developed perinephric abscess, $9.7 \%$ developed UTI, 19.3\% developed wound infections and $6.4 \%$ patients developed reno-cutaneous-urinary fistula.UTI/pyelonephritis and hydronephrosis were more in surgically treated patients. Robert et al had similar results. ${ }^{12}$ Patients with conservative therapy were not without reported complications, although a few developed in this series. Even if complications develop it can be managed with minimal invasive procedure such 
as image guided drainage for perinephric abscess, ureteric stent for reno-cutaneous-urinary fistula etc.

In one study Aragona et al found associated injuries in 19 severely blunt traumatized patients (43\%). ${ }^{9}$ Although associated organ injury was less in this study in comparison to other studies still it was considerable. Small sample size may be the cause. The ultimate goal of selective conservatism is to minimize the incidence of negative exploration without increasing morbidity from missed injury.

Wessells and Mcaninch showed simultaneous traumatic injury of the kidney and gastro-intestinal tract has been recognized as a risk factor for post operative complications. ${ }^{8}$ Missed diagnosis or improper management can lead to the morbid consequences of perinephric abscess, urinoma, fistula formation, sepsis and death. Pancreatic injury has long been recognized as a source of significant morbidity in renal trauma. This study also revealed this. In this study out of 8 liver injuries $4(44.4 \%)$ patients presented with hemodynamic instability. The rate was $100 \%$ in both spleen and pancreas injuries. Moreover all the splenic injury cases later developed reno-cutaneous-urinary fistula and the pancreatic cases developed perinephric abscess.

\section{Conclusion}

Most of the blunt renal injuries are minor and mostly due to road traffic accident. Most of these injuries can be managed conservatively. Even in patients who present with a major renal laceration associated with devascularized segments or Urinary extravasations or even identification of a large perinephric hematoma on CT is not an absolute contraindication to a trial of bed rest and close monitoring. If there are associated injuries and/or vascular injuries or hemodynamic instability, surgical intervention must be performed immediately in order to decrease morbidity and mortality and close follow-up during the postoperative period is vital. The widespread uses of CT, the availability of various minimal interventional techniques have promoted the conservative management of renal trauma whenever the patient is haemodynamically stable and prevent unnecessary exploration. Overall, conservative management of stable patients yields a lower nephrectomy rate without a significant increase in the complication rate.

\section{References}

1. Baverstock R, Simons R, McLoughlin M, 2001, "Severe blunt renal trauma: A 7-year retrospective review from a provincial trauma centre.";Can J Urol, vol. 8, no.5, pp. 1372-76.

2. Lynch D, Martinez-Pirieiro L, Plas E, Serafetinides E, Turkeri L, Hohenfellner M, 2005, "Guidelines on urological trauma."; EurUrol , vol. 47 ,no.1, pp. 1-15.

3. Broghammer JA, Isher MB, Santucci RA, 2007, "Conservative Management of Renal Trauma: A Review."; j Urology, vol.70, pp. 623- 629.

4. Moolman C, Naysaria PH, Lazarus J, Pontin A, Nicol J, 2012, "Nonoperative Management of Penetrating Kidney Injuries:A Prospective Audit."; The Journal of Urology, vol.188, pp.169-173.

5. Moudouni S M, Patard J J, Manunta A, Guiraud P, Guille F, Lobel B, 2001, "A conservative approach to major blunt renal lacerations with urinary extravasation and devitalized renal segments."; BJUI, vol.87, pp. 290-294.

6. Santucci, R. A., Wessells, H., Bartsch, G., Descotes, J., Heyns,C., Mcaninch,J. W. et al (2004) Evaluation and management of renal injuries: consensus statement of the renal trauma subcommittee. SIU Congress September 2002 Stockholm. BJU INTERNATIONAL,vol. 93, pp.937-954. 
7. Hammer CC and Santucci R A, 2003, "Effect of an institutional policy of nonoperative treatment of grades $i$ to iv renal injuries.";The Journal of Urology, vol.169, pp. 1751-1753.

8. Wessells, H. and Mcaninch ,J. W. (1996) Effect of colon injury on the management of simultaneous renal trauma, The Journal of Urology,vol.155 ,pp. 1852-1856.

9. Aragona F, Pepe P, Patane D, Mafa P, Darrigo L, Pennisi M, 2012, "Management of severe blunt renal trauma in adult patients: a 10-year retrospective review from an emergency hospital."; BJUI, vol.110, pp. 744-ᄀ748.

10. Alsikafi NF, Mcaninch JW, Elliot SP, Garcia M, 2006, "Nonoperative Management Outcomes of Isolated Urinary extravasation Following Renal Lacerations Due to External Trauma" The Journal of Urology, vol.176, pp. 2494-2497.
11. Mathews LA, Smith EM, Spimak $P$, 1997, "Nonoperative treatment of major blunt renal lacerations with urinary extfuvasation."; The Journal of Urology, vol.15, pp. 2056-2058.

12. Robert M, Drianno N, Muir G, Delbos 0, Guiter J, 1996, "Management of major blunt renal lacerations: surgical or non-operative approach?"; EurUrol, vol.30 no.3, pp. 335-339. 